Published in British Journal of Sociology, 2008, 59(1): 79-98.

The Fourth Shift: Exploring the gendered nature of sleep disruption among couples with children

Venn Susan $^{1}$, Arber Sara ${ }^{1,}$ Meadows Robert ${ }^{1}$, Hislop Jenny ${ }^{2}$

1. Centre for Research on Ageing and Gender (CRAG), Department of Sociology, University of Surrey, Guildford GU2 7XH

2. Research Institute for Life Course Studies, Keele University, Staffordshire, ST5 5BG

Lead author: Susan Venn, Email: s.venn@surrey.ac.uk, Telephone: 01483689292 


\begin{abstract}
The study of sleep has been neglected within sociology, yet may provide insights into fundamental aspects of the nature of gender inequalities. This article examines how, for couples with children, sleep is influenced by the gendered nature of caring. A key concern is not only who gets up to care for children's physical needs at night, but whether this changes with women's increased role in the labour market. Of concern also is how changes in the nature of caring for older children, as opposed to young children, may impact on parents' sleep.
\end{abstract}

This article analyses qualitative data from an ESRC funded multi-disciplinary project on couples' sleep based on in-depth audio-tape recorded interviews with 26 couples (aged 2059) with younger and older children. Additionally, one week's audio sleep diaries were completed and follow up in-depth interviews were undertaken with each partner on an individual basis.

Physical and emotional care for young children at night was largely provided by women, with a lack of explicit negotiation between partners about who provides this care, even when women return to employment. Thus, considerably more women than men continued their daytime and evening shifts, as well as undertaking an ongoing third shift of sentient activity for their family, into the night. This resulted in a fourth night-time shift where physical caring, and sentient activities continued. As a consequence, women were more likely to subjugate their own sleep needs to those of their family. Fathers did not, in general, undertake this fourth night-time shift. Those that did were more likely to be the 
fathers of young adult children who were staying out late at night, with the focus of their concerns being the safety of their children.

Keywords: Sleep; gender; caring; negotiation; couples; children 


\section{The Fourth Shift: Exploring the gendered nature of sleep disruption among couples with children}

\section{Introduction}

We talk of 'being asleep' in contrast to 'being awake' as though the former were a dormant, non-active state, and the latter were the opposite. Yet sleep is not only dynamic in terms of physiological processes, but for couples in particular, also in terms of the complex negotiation of social roles, where day to day relationships continue to be influential at night. With increased daytime demands such as longer, more stressful, working hours, greater commuting distances, and the availability of 24 hour services such as supermarkets, the length of time we spend asleep is being curtailed. A lack of sleep affects our ability to make accurate judgments, and puts us at risk in terms of safety issues, such as the dangers of driving whilst tired, and health problems, such as increasing the risk of diabetes. Being deprived of sleep can also contribute to depression, increase the risk of colds and infections and affects our ability to handle stress (National Sleep Foundation 2006).

Sleep disruption has many causes, for example stress, pain, drinking alcohol and caffeine. Yet advice given to cope with sleep disruption is often focused on improving sleep through addressing sleep 'hygiene' or habits, such as maintaining routines of going to bed and getting up at the same time every day, and cutting out coffee (Horrocks and Pounder 2006; Smith and Battagel 2004). Those who clinically treat sleep problems have largely ignored the impact that social roles have on an individual's sleep. A woman may reduce her caffeine intake to help her to sleep, but her sleep may still be disrupted by her concerns as a mother for a crying child, or as a daughter worrying about her sick and elderly parent. Sleep 
is influenced by many aspects of an individual's social context, including their gender, social role, health and changes that occur across the life course, such as having children, or returning to paid employment (Hislop and Arber 2003a). When two people share a bed, then the quality of one individual's sleep is likely to be affected by the presence of the other. Additionally, if one individual has problems sleeping, then this is likely to contribute to the disruption of their partner's sleep (Strawbridge, Shema and Roberts 2004; Beninati et al. 1999). Therefore the manner in which sleep and sleep disruptions are negotiated is important for a couple’s physical and emotional well-being.

Empirical sociological studies on women's sleep in mid and later life (Hislop and Arber 2003a, b, c) have shown how social roles impact on sleep, and studying couples' sleep has shown how sleep needs are negotiated with self and others (Meadows 2005). This article adds a further dimension to the sociological investigation of sleep by focusing on the interaction between partners in couples with children, as each partner negotiates their sleep needs and requirements around their children, and thus addresses a significant area about which there has hitherto been little sociological research.

This article focuses on couples who have children living at home ( $\mathrm{n}=18$ couples), and on accounts from couples whose children have left home ( $n=7$ couples) and examines the (largely) different ways men and women respond to interruptions to their sleep associated with children. We take as a starting point Hochschild's contention that women are more likely than men to undertake two consecutive daytime shifts, of paid employment and/or childcare, and domestic work or childcare in the evening (Hochschild 1989, 1997), as well as an ongoing third shift of emotional consciousness of their family (Hochschild 1997). Our 
research data on negotiations by couples about their sleep demonstrate that a fourth shift exists, when the first three shifts continue to take place at night. Undertaking this fourth shift can be a source of sleep disruption for both women and men, but more particularly for women. We demonstrate the importance of recognizing the gendered nature of caring and highlight how this impacts on the quantity and quality of each partners' sleep within couples. After outlining the concept of the four shifts, and reviewing literature on emotion work and caring, the methods used during this study are discussed. A diagrammatic illustration of the four shifts is given in Figure 1.

\section{The Four Shifts}

Hochschild's $(1989,1997)$ research on couples showed that the majority of employed women were engaged in working two shifts, the first their paid job, and the second their evening shift, when domestic chores, such as doing the laundry and cooking, as well as putting children to bed, take place. Although these two shifts were also undertaken by some of the men in her study, it was women who bore the brunt of these tasks. It is clear that all women, not just those in paid employment, are likely to remain responsible for household work and child care, as Oakley has recently commented, 'Most of the world's domestic work is done by women. This is as true now as it was when I undertook the study [of 1975]' (Oakley 2005: 54). However, in The Time Bind (1997), Hochschild also suggested that women were undertaking an additional third shift, that was taking place temporally during the first two shifts, that of emotional involvement with their families, which includes thinking about, worrying for, and anticipating the needs, both physical and emotional, of their families. 
In this article we examine how these three daytime shifts transfer into the night-time to result in, for some parents, a fourth shift of activities which compromises their sleep. We argue that the third shift of emotional activity, caring, worrying and anticipating family members' needs is the most influential in terms of differentiating the gendered nature of sleep disruption.

\section{Insert Figure 1 here}

\section{Emotions and caring during the night}

Emotion work, emotional labour, feeling rules (Hochschild 1983), sentient activity, caring for, caring about (Mason 1996), caringscapes (McKie, Bowlby and Gregory 1999) and socially attentive roles (Williams 2002), are all terms that have been used within academic discourses on emotion and caring to describe the activity of managing or feeling emotions. Traditionally, it is women who have been the focus of this type of emotion 'work', as they are more involved in talking and thinking about their caring responsibilities.

Men, on the other hand, are seen as more practical emotionally in that they more usually undertake physical activities which benefit the family, such as gardening or decorating, rather than the activity of engaging in emotional involvement with those they are caring for (Coltrane 1998). But others have argued that men do engage in emotion work, but on themselves in an attempt to conform to the ideology of 'being a man', for example, by working on their emotions to keep the stresses of their careers to themselves, rather than sharing the problems with their partner. Emotion work for men, it is suggested, is selforiented rather than other-oriented in that it is undertaken on themselves, rather than on others (Weiss 1990). 
Emotion work and caring then, it has been argued, have been socially constructed as a feminine activity in both the home and the workplace, with Finch and Groves (1983) suggesting that this is so primarily because of the female capacity to empathize and relate to the recipients of their care. But it is not only the female capacity to be caregivers within the family which leads them to dominate this arena; it is also that there is a perception of a lower market value related to their time, particularly in relation to other members of the family, which leaves them better situated to undertake this activity (Fox and Murry 2000). Hochschild $(1983,1997)$ too has suggested that women, in particular, rely on using their emotions because their lack of power and status in society leaves them with fewer resources than men. One resource they can utilize is their emotions and feelings, but by relying on these as a resource they then become more vulnerable to 'attacks' on their emotions and feelings.

In using the term 'emotion work’ Hochschild (1983) refers to the use of emotions as a means of exchange between a caregiver and the recipient of that care without feeling, such as when flight attendants put on a smile for the benefit of their passengers to increase customer satisfaction. The implication is that if they did not fulfil their 'role' as providers of care, they would be failing in their employee responsibilities. Emotion 'work' then implies the management of emotions for a specific aim, rather than a way of achieving empathy with the recipient of the emotion. Others have also used the term emotion work to illustrate caring in areas outside the family, such as Sanders (2004) whose sex workers used it to cope with the repulsion of their situation, O’Brien (1994) whose nurses undertook emotion work on their 
patients to fulfil duties and complete tasks, and Treweek (1996) whose care assistants did emotion work to cope with frail and elderly nursing home residents.

However, emotion work has not just been used to describe 'front stage' social interaction, it has also been extended to stand for emotional involvement at more than just the dramaturgical level (Goffman 1959). James (1989) has suggested that women undertake emotion work by organizing the household, undertaking domestic chores, and caring for or worrying about family members. Similarly, DeVault's (1991) study of the preparation of family meals and Williams' (2003) study on managing chronic illness among adolescent children imply that emotion work is being undertaken by women on their family members. So for some writers the boundary between emotion work in 'front stage' terms and caring, worrying and feeling for the family has become blurred. Yet there is still the implication that emotion work undertaken in the private arena of the home is perceived as being more genuine, more authentic and of greater intrinsic value, than that taking place in the public arena, leaving still a suggestion of a dichotomy, between 'emotion work (or labour)' and emotional 'feeling'.

Mason (1996) has attempted to deconstruct this dichotomous viewpoint by suggesting, in her study on commitments between family and kin, that women were noticeably better at recognizing and anticipating the needs of others:

'Jane [daughter] seems to know what wants doing, and do it. I mean Jack [son] would come over and cook a meal and bring the food with him. But he hasn't much sense of reality as to what sort of meal you want'. (Mason 1996: 28) 
For Mason ‘sentient activity’, and its relational activity, active sensibility, are actionbased expressions of the emotional involvement and (subsequent) caring experienced within families. Thinking about, being alert to and recognizing the needs and wants of those you care for is a feeling which is not just related to the physical expression of care, such as the emotion work of flight attendants, or giving a child a bottle of milk at night. Caring within families is therefore not a dichotomous activity of either work, or feeling, because of the normative belief that one should be committed to members of your family. Active sensibility arises from a commitment to the person you care for, which in turn engenders sentient activity.

Sentient activity, therefore, is more expressive of what caring within families really is. It is not in actuality 'work' because it is a way of engaging with those that we love or care for and as such restores a sense of value to the caregiver. Work implies a chore, a labour, yet sentient activity suggests that it is a sense of commitment to care as a result of a normative sense of responsibility for one’s family, which motivates the emotion 'work'. By recognizing the sentient actions that are undertaken by those in a caring role, Mason's sentient activity recognizes that emotional involvement takes place in many different ways and at many different times.

Ultimately, therefore, the fourth shift arises out of a sense of responsibility by parents which continues into the night, as a further expression of thinking about, caring for and anticipating the same family needs that take place during the day. This article will illustrate through empirical data, framed within the concept of sentient activity, how women are still 
reflecting the gender stereotypical role of main carer throughout the lifecourse and which has implications for their sleep. This is in spite of changes in their own circumstances, such as returning to paid employment.

\section{Methods}

This article analyses data from an ESRC funded research project examining the negotiation of couples' sleep. ${ }^{1} \quad$ As the focus of the study is the interaction of two individuals sleeping together, couples were initially interviewed jointly, then again 4-6 weeks later as individuals but separately, providing a greater opportunity to explore in detail the reality of couples' sleep from both partners' points of view. Previous studies of couples' sleep have been clinically focused and used individualized, structured self-completion questionnaires (Cartwright and Knight 1987, Wiggins et al 1990). They have not examined the interaction that takes place between couples.

Heterosexual, couples were recruited from a variety of sources, including advertising, leaflet drops, acquaintances of the researchers, and snowballing. An attempt to recruit from different socio-economic groups and with varying educational qualifications was made in order to ensure that couples with different lifestyles were interviewed. The respondents ranged in age from 20 to 59 years, so that not only did they represent different chronological ages, but also stages in their relationship and phases of the life course. The aim was to capture changes that occur during the life course, such as having children, giving up employment to look after children, recommencing employment, or caring for elderly or disabled relatives, and how these influence each partners' sleep. 
This article focuses solely on those couples who have had children, whether they were living at home at the time of the interviews ( $\mathrm{n}=18$ couples) or had moved away, although their children often returned home for extended visits ( $n=7$ couples). Whilst it could be argued there is a potential for mis-reporting by including retrospective accounts from the 7 couples whose children no longer permanently lived in the parental home, these accounts were cross-validated by data from the couple interviews and in the separate follow-up interview with each partner.

Couples were paid $£ 100$ as compensation for their contribution to the study (which also involved collection of physiological data). Respondents with chronic illness, clinically diagnosed sleep disorders or who were pregnant were excluded from the study.

All the interviews were audio tape-recorded and took place in the couples' own home by a male and female researcher, and lasted approximately one to one and a half hours. A first joint interview with the couple explored topics such as the quality, quantity and nature of sleep, with particular emphasis placed on sleep expectations and how this compared with their sleep reality, external influences on the quality of couples' sleep, such as children, caring for other members of the family, pets and so on. Questions were also asked about physiological influences on the quality of sleep, such as the need to go to the toilet, snoring, and pain. Respondents were then asked to complete a daily audio sleep diary for one week, a method used for recording an individual's subjective experience of sleep that proved successful in previous research (Hislop and Arber 2003a; Hislop et al. 2005). A follow up interview took place approximately 4-6 weeks later with each partner being interviewed 
separately, but concurrently. The interviewer and partner being interviewed were gendermatched. This follow-up interview explored in more detail issues that arose during the couple interview and which partners had recorded in their audio sleep diaries.

All interviews and audio diaries were transcribed and the transcriptions were then imported into qualitative data analysis software (NVivo). An inductive analytic approach was used whereby key concepts and findings were built up from the empirical data, rather than using pre-existing hypotheses to examine the data. A grounded theory approach (Glaser and Strauss 1967) was used to identify categories and ultimately concepts from the qualitative data, which had been collected in three different ways (couple interviews, individual interviews and audio-diaries).

The data were open coded and categorized until core categories were revealed, followed by a process of examination and re-examination to ensure that all categories had been captured. Axial coding then took place (Strauss and Corbin 1994), which identified those categories which were related together in order to reveal underlying concepts. In order to ensure data robustness, the transcript data were constantly checked for categories or themes which were not relevant or contradicted those already identified. Finally, selective coding revealed the main concepts within the data.

To protect the anonymity and confidentiality of the respondents a naming convention has been adopted which indicates the couple number, gender and whether the data were from the couple interview (C), the individual interview (I) or from the audio diary (AD). An example of naming conventions is $1 \mathrm{~F}(\mathrm{I})=$ couple number one, female, individual 
interview; $5 \mathrm{M}(\mathrm{C}) \quad$ = couple number five, male, couple interview and $4 \mathrm{M}(\mathrm{AD})$ couple number four, male, audio diary.

Ethical approval was obtained from the University of Surrey Ethics Committee. Written informed consent was obtained from each respondent in advance of the interview and respondents were reassured that their responses would be kept entirely confidential. Additionally, advice was sought from a family therapy counsellor prior to commencing the interviews so that any possible conflict that arose between partners in the couple interview could be handled appropriately by the interviewers.

\section{A Night-time of Activity - Moving through the shifts}

Having children will impact on parental sleep, that is well known, but it is on whom in particular that impact largely falls which is the subject of this section. For the couples in this study, wakefulness by younger children at night was most commonly as a result of physical needs, such as hunger, illness or the child's own disrupted sleep. As expected, there was, for most of the parents, a gender divide in the way mothers and fathers responded to this wakefulness. Mothers with younger children continued at night to undertake similar physical activities to those they undertook during the day:

$1 \mathrm{~F}(\mathrm{C}) \quad$ One [child] was poorly the other day and I changed the duvet and the bed, and she had a friend in and I didn't wake anybody. (Daughter aged 8 years)

29F(AD) Our five year old walked into the room at I think it was 2am and I sort of sat up and said "who's that?", and he was upset about something, so 
I took him back into his room settled him back into bed. (Son aged 5 years)

But it was not only physical caring activities that continued at night for the women in this study. The third shift of sentient activity (Mason 1996), that is hearing, noticing and being attuned to the needs of their children continued during the night, which often left the mothers with significantly disrupted sleep:

$1 \mathrm{~F}(\mathrm{C}) \quad \mathrm{I}$ know normally before they get up - I am awake before they have even shouted, because I know it’s coming [waking up]. (Three children, 10, 8 and 2 years)

5F(C) I can be in a deep sleep and they will say "mum" and I will be up and awake straight away....But it is weird I can be in a real deep sleep. But if they want something, I am awake straight away. (Three children, 7 and 3 years, and 15 months)

But whilst for the mothers the physical demands made on them at night declined as their children grew up, the sentient activity they undertook did not. Those mothers with older children were at best, as likely as the mothers of young children to be listening out for them in the night, and at worst considerably more deprived of sleep than when their children were younger: 
24F(C) I think having children always make you more prone to surface anyway. I think when they are little you get so used to waking up at the slightest squeak. (Two sons aged 25 and 23 years)

31F(C) If they do go out - supposing our daughter is in town, we will go to bed and we will be fast asleep. But then we will wake up early in the morning, and I will tip toe into her room, and if she is not there then we will panic, but she is usually there and I will come back again so ... we do worry indirectly (Daughter aged 20 years)

Interviewer Which was more difficult to deal with when they were coming in late as teenagers or when they were small children?

28F(C) I think teenagers. (Son and daughter 21 and 19 years).

Interviewer Okay, why do you think that?

28F(C) Only because of the uncertainty. I think it is the uncertainly side of things really. Not knowing, I mean it is the other things, it is not just like when they were coming in. It is like who are they out with.? Who is driving?

And even when their children have left home, sentient activity by mothers often continued to disrupt their sleep:

18F(C) Well I am a worrier [at night] about different sort of things. Our daughter has a money problem that sort of really stresses me out. (Two married daughters aged 32 and 29 years) 
So for mothers of young children there was a continuation of both the second and third shifts of physical and sentient activity into the night, resulting in a fourth shift which disrupts their sleep. For mothers of older, adult children, however, it was the continuation of the third shift which dominated the night as they often lay awake imagining their children in a car accident and unable to fall asleep until their children are safely home and in bed, as illustrated by the following quotation:

6F(C) Well I think when they were smaller it [physical care] was more frequent, but it was just to feed them or take them to the toilet or change their nappy all those kinds of things, whereas now you have got the worry element. (Son and daughter aged 17 and 20 years)

In contrast, the fathers, of young children were much less likely to be as intensely involved in night-time sentient or physical caring activities, and most claimed they slept through night-time disturbances:

$1 \mathrm{M}(\mathrm{C}) \quad$ My thing is I can sleep anywhere. Generally speaking I get a good night's sleep wherever I am.... Once I'm asleep that's that really. (Three children, 10, 8 and 2 years)

3F(C) I mean if there is ever a problem [with the children], if they want a drink it’s MUMMY! (Two daughters aged 9 and 7 years)

Interviewer Do you wake up? [to father]

3M(C) Never! [laughter] 
In our sample, only two fathers were actively involved in responding to their younger children's needs, and these cases appeared to be linked to having children with a significant health problem. One father, whose five year old son has a degenerative kidney disease, shared responsibility for coping with his young son's wakefulness. He and his partner had developed a system where there was mutual anticipation and response to their son's needs:

34M(AD) (Son) was in our bed again. We're allowing him to sleep in the bed at the moment, because he's not very well. He seems to be going through some sort of a personal crisis. I think we're going to be stricter with him tonight and make him sleep in his own bed. That's what we're telling him. (Son aged 5 years)

Another example of fathers caring for younger children was a father of autistic twins who shared caring for them at night with his partner when they were born, and became the main night-time carer after their diagnosis as autistic:

38F(C) We used to wake them up at the same time (when they were first born) and feed them so we both had to get up then, didn’t we? (3 children, one aged 7 years and twins of 4 years)

Interviewer And so do you both get up to the children? Or is one of you ... if they wake up in the night.

$38 \mathrm{M}(\mathrm{C}) \quad$ It is generally me at the moment... 
$38 \mathrm{M}(\mathrm{C}) \quad$ Whenever the twins wake up now or for whatever reason I just get up...

38M(AD) The twins woke up. They had a restless night...

There are numerous possibilities as to why this couple have reached this arrangement, including the fact that the mother works evening shifts, and the children are very physically demanding during the day as a result of their autism. This father then was responding to his children's physical needs, but as can be seen from his last three statements there was no indication that he was undertaking sentient activity. He was responding to their needs, not anticipating or thinking about them.

Mothers of younger children are, then, more likely to be undertaking both sentient and physical activity at night. They continue their role as nurturer and carer into the night, to the detriment of their own sleep. When a younger child wakes up, whether because of illness, bad dreams or just to cry out, it is most often the mother who wakes and gets up in response. The exception to this is when a child has a serious illness or disability, when fathers are more likely to become involved in dealing with children's needs at night, albeit responding to physical demands, rather than anticipating or worrying about their children's needs. Mothers of older children, whilst free of dealing with the physical requirements of their children at night, continue caring and worrying about their children until they are safely at home. In the next section we will suggest that it is at this point in their children's lives, when they are older and more independent, that fathers engage in sentient activity at night and so, too, take part in the fourth shift. 


\section{Fathers in the Fourth Shift}

Concern for family security is often remarked upon as being stereotypically gendered, in that men fulfil the role of family protector, and women support their partner in this role. Women are likely to build up social relationships within their community to support their family, whereas men's approach to family safety is limited to their own household (Fox and Murry 2000). The fathers in this study with young children, who are unlikely to leave the safety of their home and be at risk in the middle of the night, did not need to fulfil the role of protector. Whatever disturbed their young children was in most cases related to the child's physical needs and was dealt with by their mother. However, for those fathers with older, more independent children, the role of protector at night became more crucial. It was common for the fathers to remark on how they could not sleep until they knew their teenage children were home safely and were in bed, and that they would lay awake listening for them to return. Driving, or being driven at night, was frequently quoted as a major concern:

6M(C) They are out to ridiculous hours in the morning and so you go to sleep at 10.30 or whatever, but always on your mind they are both driving and subconsciously I suppose... and if you wake up at say at 12, and you think they are not in yet. So, of course, it starts...[worrying for their safety] (Son and daughter aged 17 and 20 years)

9M(C) I was always more frightened about him being in other people's cars. [at night]. (Son aged 18 years) 
One couple in particular illustrated the shift in responsibility for night-time physical and sentient activity that takes place as their children have grown up. Unusually in this study amongst the couples with children, this couple shared getting up to their children in the night when they were younger. But whilst they took it in turns to look after the physical needs of their children when they were younger, both partners recognized that the father is more often disturbed at night by anxiety about their older, teenage children:

$17 \mathrm{M}(\mathrm{C}) \quad$ We took turns [to get up to the children when they were younger]. If one of them was ill, one would get up one night, one would get up the next. (Son and daughter aged 17 and 21 years)

17F(C) You do now more than me. Say that M[son] is not very well, you get up and go and check him don’t you.

Interviewer So worrying about the kids has that had any effect on your sleep?

17F(C) It has mine. You say I worry too much, don't you? [to husband]

17M(C) You worry too much. Yes, I do, I really worry about them, I have always got them on my mind. So may be that is why I am such a light sleeper, I don’t know.

Interviewer So does it have more impact on your sleep now do you think, the kids? 
17F(C) I think it is probably worse now. I don’t know. I think it is now more than when they were little. I would say now me personally. I don't know about you.

Interviewer Yes what about you? [to husband]

17M(C) I let her worry for me. I mean I worry. But I don’t let her know I worry. I just worry in my own way.

This dialogue between the couple illustrates how the mother's worrying and concerns for her children has intensified as her children have grown up ('I think it is now more than when they were little'). But it also shows how her husband has recognized that he is now worrying about whether his children are safe or not ('I have always got them on my mind'), and that he has moved from sharing the physical activity of getting up for ill children when they were younger to include worrying about how and where his children are at night.

We have suggested that part of the reason for this change in emphasis of fathers of older children also 'working' the fourth shift may be linked to their perceived status in the male protector role. But it is, nevertheless, more complex than a straightforward re-play of hegemonic masculinity (Connell 1987). It is also perhaps that Mason's active sensibility offers an explanation for the inclusion of fathers of older children in sentient activity (1996). As she suggested, a commitment to a person engenders a predisposition to care for that person and take on responsibility for them. We suggest the perceived role as family protector, allied with an increased commitment to their children's welfare as mothers return 
to work, led to the fathers becoming engaged to a greater extent in thinking for and anticipating their older children's safety. It is not to say the mothers were not similarly engaged, but that it was also undertaken by their partners:

31M(C) Is he [son] lying in a river drunk? Which he did once on his eighteenth birthday.... He got into the river and out of the river but after that we thought well next time he might just fall in the river and then die you know........ (Son and daughter, 20 and 18 years). [author's emphasis].

32F(I) When they are under your roof it is fine. I know when they went out I used to fall asleep, I think, but I woke immediately they came back. Immediately. And I used to wake sometimes and realize that they weren’t back and think, you sort of set your alarm and when they weren’t back, I used to wake in shock.... Mothers are very tuned in to their children. I know I always was. And my mother said she was. So you are always aware of the fact that they are safely in bed or not. There always seems to be some sort of consciousness about that I think. I asked my mum when she was 80 if the umbilical cord ever got cut and she said 'never'. (Two sons 29 and 23, one daughter 27 years)

However, for mothers engaging in sentient activity, who are joined by their partners in this activity, there is an increased possibility of disruption to their sleep as she is not only disrupted by her own concerns, but also by her partner's expression of his. One father went 
so far as to expect his children to come in and talk to them when they got home, even if it was in the middle of the night:

6M(AD) $\quad \mathrm{M}$ (son) came in around two thirty, we talked for about five minutes and it took about an hour to get back to sleep again. (Son aged 17 years).

His wife explained in the individual interview that by routinely chatting to their teenage son when he came home at night, her husband is also disrupting her own sleep:

6F(I) He [husband] initiates it [chatting] more than I do, because he is quite disturbed [by son coming in] and he will say 'are you awake?' And I usually am, but I won’t let him know I am. I will keep quiet unless he does speak and I try to pretend I am not awake, because I desperately want to get back to sleep.

It has been suggested that men are less likely to engage in the emotional activity of caring in terms of worrying, anticipating and thinking about their family, but that they do emotion work on themselves (Weiss 1990). However, men with older children in this study clearly demonstrated they were undertaking sentient activity at night, not only on themselves in fulfilling their perceived role as protector, but also on members of their family. They have moved from leaving the responsibility of night-time childcare for young children to their female partners, to sharing in that responsibility by demonstrating sentient activity for their children. 


\section{Negotiating the fourth shift - changing dynamics across the lifecourse}

Other changes that take place across the lifecourse also have an effect on how parents negotiate the fourth shift. As the children within these families became less dependent, for example sleeping through the night and starting school, many of the mothers returned to fulltime employment or, in some cases, started further education. As with Hochschild's (1989, 1997) study on working parents, there was some evidence in this study of a re-negotiation of responsibilities when mothers returned to work, so that the withdrawal from sole responsibility for childcare by the mothers was complemented by increased commitment by the father's to share in that childcare.

Our study illustrates how the dynamics of a couple’s relationship may alter during the life course with changes such as having children, or returning to paid employment having an influence on the process by which negotiation for night-time responsibilities takes place, and the subsequent impact this has on sleep.

\section{$\underline{\text { Young children - implicit and explicit negotiation }}$}

For couples with young children where the wife did not work, childcare largely remained the responsibility of the mother and her sleep needs were subjugated to that of her children and male partner. The negotiation that led to mothers taking on the role of having sole responsibility for the fourth shift was, for the most part, implicit:

40M(I) She may get woken up a little bit more than me, because there is this understanding that I have got a lot of travelling to do and safetywise I 
need to get slightly more sleep than she. (Two sons aged 5 and two and a half years)

32F(I) I used to go and feed the baby in another room because he had to go to work and I was at home. (Two sons 29 and 23, one daughter 27 years)

Interviewer Did you discuss it at all? [who gets up in the night] (Two sons, 20 and 18 years)

7F(C) No, we never discussed it, did we? Not really.

7M(C) I can’t remember.

Not all negotiation was implicit, as illustrated by this couple recalling that there had been a discussion about parental responsibility during the night:

3F(I) We did talk about it and we came to a joint decision that it was accepted he is the one that works all day, so he is the one that needs his sleep at night. (Two daughters aged 9 and 7 years)

However, it was not the norm to discuss responsibilities for night-time childcare, and among these couples, the negotiation never resulted in the father becoming the sole carer at night. Also, a re-negotiation of night-time responsibilities rarely took place when family roles changed, such as the mother returning to paid employment, which we go on to discuss in the next section. 


\section{Women returning to work - re-negotiation?}

In spite of the acceptance within most couples that, as the father was working all day, the mother would get up to young children in the night, there was only very rarely a renegotiation of this situation when the female partner returned to paid employment or full-time education. Even though the children were often still quite young and in need of attention at night, it was more common for the working women to continue getting up:

7F(C) I started working part time when they were at school, both of them were at school. And even then I was always home to pick them up. (Two sons, 20 and 18 years)

Interviewer And you still got up to them in the night?

7F(C) Yes. Yes.

Interviewer $\quad$...how did that come about?

7F(C) Well he [husband] didn’t wake up, so...

The impact this has on the working mother's sleep is illustrated in the following excerpts from the audio diaries for the same night recorded by a mother and father who both work full time:

40F(AD) [Youngest son] woke up at five past four and it took ten minutes to get him to settle and I went back to bed at four-fifteen. [Oldest son] woke up at twenty past five and came in bed with us and, umm, and woke up at about five to seven, but we actually got up at twenty-five past seven, 
so we dozed for a little while, umm, talked to [oldest son] a little bit. (Two sons, 5 and 21/2 years)

40M(AD) But umm, I don’t recall [youngest son] or [oldest son] waking me up during the night. Oh yes, actually [oldest son] did come in didn’t he, telling us about he had a bad dream or something, I can’t remember what time that was either.

In this couple, the mother had to deal with the constant interruptions by her sons at night whilst the vague awareness of these interruptions by the father illustrates how little account is taken of the need for the mother to have sufficient sleep to function at work the following day. Thus, women who had returned to work, whether full or part-time, continued to look after the physical needs of their children at night, and did not re-negotiate changes to the way childcare was dealt with at night.

Not all of the women failed to impress on their partners the need to be aware of their change in employment status. These women felt it was important that the combination of increased economic contribution to the family, and the longer hours they spent at work on the first shift were recognized, and led to increased expectations of help by their husband within the family home. However, the failure by their partners to recognize this led to an accompanying frustration and resentment about the lack of help they were receiving:

3M(C) How do I sleep? To lay in bed, you (to partner) never let me stay in bed, so I am not given the opportunity. (Two children, 7 and 9 years) 
Interviewer So, you don't let him stay in bed?

3F(C) Well, it is just that it really upsets me that as soon as I wake up, you know what I mean, I don't come downstairs, I don't make myself a cup of tea, I don't sit down and watch the television ... you're on the go the whole time and I keep thinking that if I've been running around [noise like dedededede] doing everything, then after an hour I get a bit, I get angrier and angrier, I think 'why am I doing all this, why am I doing this' so I go and wake him.

8F(I) What frustrates me is he wakes me up, has a cup of tea and then goes back to sleep. (8 year old triplets)

Interviewer And then by that time...

8F(I) Yes, the children are up and I am up, so I have asked him not to do that [go back to sleep]

40F(I) Sometimes I kick him [when children wake up], if it is about three or four times [they wake up in the night]. It is, like, your turn! (Two sons aged 5 and two and a half years)

Negotiating who undertook childcare at night, whether implicit or explicit, rarely resulted for these couples in an equitable share of the night-time shift. Non-working mothers perceived it as reasonable to argue that they are better suited to getting up in the night, if their partners have to go to work. However, on returning to work, there was seldom ever a renegotiation of night-time responsibilities by the women, leaving them continuing to 
undertake both aspects of the fourth shift (physical and sentient). This often led to frustration and resentment among the women in this study.

\section{Discussion and Conclusions}

The couples in this study revealed that far from the partnership bed being a haven for peace and rest from daytime activities, the influence of social roles and the social context of couples' lives continue during the night and have a significant impact on the quality and nature of their sleep.

Hochschild (1997) has suggested that three shifts exist for women, that of daytime work (either paid employment or childcare), evening work (continuing household duties), and emotion work (thinking about the needs of their partner or children whilst undertaking their paid employment or household duties). This article has suggested that a fourth shift exists, where the previous two shifts of paid employment/household duties and child care, and a third shift of caring or in Mason’s (1996) terms, sentient activity, are continued at night-time. This results in significant sleep disruption for both men and women with children, but more particularly for women, regardless of the age of their children.

The women in this study demonstrated that they, more than their partners, were more likely to respond to their children's physical needs at night, such as changing the bed or responding to their cries. But their role as mother, nurturer and carer also resulted in them undertaking sentient activity at night, so that they worried about and anticipated their children needing them, often resulting in significant disruption to their own sleep. Whereas this sentient activity carried on at night for women with children of all ages, only men with 
teenage or young adult children appeared to undertake similar sentient activity at night. The focus of this activity for men, though, was on acting in accordance with with their self perceived role as family protector. In situating themselves in this socially constructed role as male breadwinner/protector, they engaged with a sense of responsibility for safety of their young adult children when they were out late at night. When their small children were safely tucked up in bed, and any awakenings would be dealt with by their mother, there was no need for them to take on this role at night. However, when their children achieved greater independence the fathers felt increased responsibility and commitment for their children, and often lay awake worrying for their safety when outside the family home. Unfortunately for the mothers though, their wakeful partners often contributed to their own sleep disruption.

Negotiating who complies with the roles of physical caring and sentient activity at night was more often than not implicit, leaving women with young children more likely than their partners to be active during the fourth shift. When the female partner returned to employment, as their children grew older, there was little or no re-negotiation over night-time responsibilities, leaving many of the women resentful of the increased demands on them during the day, undertaken in addition to their continued night-time caring activities.

The sociological study of sleep provides a further realm in which to explore how gender influences approaches to caring and how social roles are negotiated within couples. Far from being a realm where activities cease, the night can be seen as another place, both spatial and temporal, where gender differences are expressed and revealed. 


\section{Bibliography}

Beninati, W., Harris, C.D., Herold, D.L. and Shepard Jr, J.W. 1999 'The Effect of Snoring and Obstructive Sleep Apnea on the Sleep Quality of Bed Partners', Mayo Clinic Proceedings 74(10): 955-8.

Cartwright, R.D. and Knight, S. 1987 'Silent Partners: Wives of Sleep Apnoeic Patient', Sleep 10(3): 244-8.

Coltrane, S. 1998 Gender and Families, Thousand Oaks, California: Pine Forge Press.

Connell, R.W. 1987 Gender and Power, London: Polity Press.

DeVault, M.L. 1991 Feeding the Family: The Social Organisation of Caring as Gendered Work, Chicago: University of Chicago Press.

Finch J., and Groves D. 1983 A Labour of Love: Women, Work and Caring, London: Routledge and Kegan Paul Plc.

Fox G.L. and Murry, V.M. 2000 'Gender and Families: Feminist Perspectives and Family Research’, Journal of Marriage and the Family 62: 1160-72.

Glaser, B.G. and Strauss A.L. (1967) The Discovery of Grounded Theory: Strategies for Qualitative Research, Chicago: Aldine.

Goffman, E. 1959, Presentation of Self in Everyday Life, London: Penguin Books.

Hislop, J. and Arber, S. 2003a 'Sleepers Wake! The Gendered Nature of Sleep Disruption Among Mid-Life Women’, Sociology 37(4): 695-711.

Hislop, J. and Arber, S. 2003b 'Understanding Women's Sleep: Beyond MedicalizationHealthicization?’, Sociology of Health and Illness 25(7): 815-37.

Hislop, J., Arber, S. 2003c 'Sleep as a social act: A window on gender roles and relationships' in S. Arber, K. Davidson, and J. Ginn, J. (eds), Gender \& Ageing: Changing Roles and Relationships, Maidenhead: McGraw Hill/Open University Press: 186-205.

Hislop, J., Arber S., Meadows R., and Venn, S. 2005 'Narratives of the Night: The Use of Audio Diaries in Researching Sleep', Sociological Research Online, 10(4) http://www.socresonline.org.uk/10/4/hislop.html, 13 October 2007.

Hochschild, A. 1983 The Managed Heart, Berkeley: University of California Press.

Hochschild, A. 1989 The Second Shift, London: Penguin. 
Hochschild, A. 1997 The Time Bind, When Work Becomes Home and Home Becomes Work, New York: Owl Books.

Horrocks N. and Pounder R. 2006 'Working the Night Shift: Preparation, Survival and Recovery', Royal College of Physicians of London Guide, The Lavenham Group, Suffolk.

James, N. 1989 'Emotional Labour: Skill and Work in the Social Regulation of Feelings', The Sociology Review, London: Routledge.

Mason, J. 1996 'Gender, Care and Sensibility in Family and Kin Relationships' in J. Holland and L. Adkins (eds) Sex, Sensibility and the Gendered Body, Basingstoke: MacMillan.

Meadows, R. 2005 'The Negotiated Night: An Embodied Conceptual Framework for the Sociological Study of Sleep', The Sociological Review 53(2): 240-54.

National Sleep Foundation 2006, http://www.sleepfoundation.org, 13 October 2007.

McKie, L., Bowlby S., and Gregory, S. 1999 'Connecting Gender, Power and the Household' in L. McKie, S. Bowlby and S. Gregory (eds) Gender, Power and the Household, Basingstoke: MacMillan .

Oakley A. 2005 The Ann Oakley Reader: Gender, Women and Social Science, Bristol: The Policy Press.

O'Brien, M. 1994 'The Managed Heart Revisited: Health and Social Control', The Sociological Review 42(3): 393-413.

Sanders, T. 2004 'Controllable Laughter: Managing Sex Work Through Humour', Sociology 38(7): 273-91.

Smith, A.M. and Battagel, J.M. 2004 'Non-apneic Snoring and the Orthodontist: the Effectiveness of Mandibular Advancement Splints’, Journal of Orthodontistry 31(2): 115-23.

Strauss, A. and Corbin, J. 1994 'Grounded Theory Methodology: An Overview' in Norman K., Denzin and Yvonna S. Lincoln, (eds) Handbook of Qualitative Research, Thousand Oaks, Ca.: Sage Publications.

Strawbridge, W.J., Shema S.J. and Roberts R.E. 2004 'Impact of Spouse Sleep Problems on Partners', Sleep 27(3): 527-31.

Treweek, G.L. 1996 Emotion Work, Order and Emotional Power in Care Assistant Work, Oxford: Blackwell.

Weiss, R. 1990 Staying the Course, New York: Fawcett Columbine. 
Wiggins, C.L., Schmidt-Nowara, W.W., Coultas, D.B., Samet, J.M. 1990 'Comparison of Self- and Spouse Reports of Snoring and Other Symptoms Associated with Sleep Apnea Syndrome', Association of Professional Sleep Societies 13(3): 245-52.

Williams, C. 2002 Mothers, Young People and Chronic Illness, Aldershot: Ashgate Press.

Williams, C. 2003 'Alert Assistants in Managing Chronic Illness, the Case of Mothers and Teenage Sons', Sociology of Health and Illness 22(2): 254-72.

\footnotetext{
${ }^{1}$ Arber, S., Hislop, J. and Meadows, R. 'Negotiating Sleep: Gender, Age and Social Relationships Among Couples', ESRC, RES-000-23-0268
} 